\title{
SOME COMMENTS ON ACCELERATOR MASS SPECTROMETRY
}

\author{
Harry E Gove \\ Professor Emeritus of Physics and Astronomy, University of Rochester, Campus Station, New York 14627, USA and \\ Adjunct Professor of Physics, IsoTrace Laboratory, University of Toronto, 60 George St., Toronto, ON, M5S 1A7, Canada. \\ Email: gove@nsrl.rochester.edu.
}

\begin{abstract}
This paper discusses some aspects of the development of accelerator mass spectrometry (AMS), the international conferences that have been held, and the books that have been written on the subject. It also mentions some details of the technique and its strengths. Some of the interesting measurements that have been made recently are covered, and finally, it presents some thoughts on future developments.
\end{abstract}

\section{THE DEVELOPMENT OF ACCELERATOR MASS SPECTROMETRY}

Accelerator mass spectrometry (AMS) was originally developed to detect radiocarbon in samples many times smaller than required by the Libby decay counting technique and, it was hoped, in organic samples that "died" much longer ago than the 60,000-year or so age limitation of the Libby method. Almost from its inception AMS involved the use of tandem electrostatic accelerators normally employed for research in nuclear physics and, later, small tandems specifically designed to detect long-lived radioisotopes. Some early work used cyclotrons, but at present and probably well into the future, tandem electrostatic accelerators are the ones of choice.

The use of tandem electrostatic accelerators for the direct detection of ${ }^{14} \mathrm{C}$ in natural organic samples is particularly advantageous because it allows the discrimination against the two mass- 14 interferences. These are ${ }^{14} \mathrm{~N}$ and the mass 14 molecules ${ }^{12} \mathrm{CH}_{2}$ and ${ }^{13} \mathrm{CH}$. In the case of ${ }^{14} \mathrm{~N}$, for many years people using tandem accelerators for nuclear research, when they wanted beams of ${ }^{14} \mathrm{~N}$, tuned the negative ion source to ${ }^{14} \mathrm{NH}^{-}$rather than ${ }^{14} \mathrm{~N}^{-}$. It was assumed that the latter negative ions were sufficiently unstable as to not allow them to be accelerated. Who, among tandem users, actually first discovered they were unstable is open to debate. It was, however, later definitively demonstrated to be the case (Purser et al. 1977). Remarkably enough, in searching the literature for another purpose, I came upon a paper by Sir John J Thompson published in Philosophical Magazine (1912:209). In this paper Thompson, who won the Nobel Prize for physics in 1906 for his discovery of the electron, reported the results of experiments in which he deflected positively and negatively charged atoms in electric and magnetic fields. He noted:

I have never observed any indications of negatively charged helium, argon, nitrogen or mercury, however strong the lines corresponding to the positively charged atoms may have been. On the other hand, the atoms of hydrogen, carbon, oxygen, sulphur, chlorine are conspicuous for the readiness with which under ordinary conditions they acquire a negative charge.

Clearly, from the point of view of AMS, Sir John was, albeit unwittingly, well before his time!

In the case of the mass-14 interfering molecules ${ }^{12} \mathrm{CH}_{2}$ and ${ }^{13} \mathrm{CH}$, one of the great advantages of AMS employing tandem electrostatic accelerators is the need to convert the negative ions to positive ions in the terminal for the second acceleration. In this conversion, if three or more electrons are removed from the molecule in addition to the electron that made it a negative ion, it disintegrates by a coulomb explosion and the resulting fragments are readily separated from the wanted ${ }^{14} \mathrm{C}$ by electric and magnetic deflection at the high energy end of the accelerator. The destruction of molecules is a property of AMS employing tandem electrostatic accelerators that is of crucial importance in the ultrasensitive detection of every isotope in addition to ${ }^{14} \mathrm{C}$ for which AMS is used. 
Although at the beginning the impetus was to detect ${ }^{14} \mathrm{C}$, it was soon realized that many other radioisotopes and even stable isotopes could be usefully detected by AMS in the matrices of more abundant elements. In fact, as soon as it is demonstrated that AMS can measure an isotope at high sensitivity for a particular application, many other applications for measurements of that isotope soon blossom. The radioisotopes detected by AMS to date include ${ }^{10} \mathrm{Be},{ }^{14} \mathrm{C},{ }^{32} \mathrm{Si},{ }^{26} \mathrm{Al},{ }^{36} \mathrm{Cl},{ }^{41} \mathrm{Ca},{ }^{99} \mathrm{Tc}$, ${ }^{129} \mathrm{I},{ }^{210} \mathrm{~Pb},{ }^{210} \mathrm{Po},{ }^{226} \mathrm{Ra},{ }^{230} \mathrm{Th},{ }^{231} \mathrm{~Pa},{ }^{234} \mathrm{U},{ }^{236} \mathrm{U},{ }^{237} \mathrm{~Np},{ }^{237} \mathrm{Pu}$, and ${ }^{244} \mathrm{Pu}$. Of these, the ones measured most often are ${ }^{10} \mathrm{Be},{ }^{14} \mathrm{C},{ }^{26} \mathrm{Al},{ }^{36} \mathrm{Cl}$ and ${ }^{129} \mathrm{I}$. Stable isotopes include $\mathrm{Ru}, \mathrm{Cs}, \mathrm{Rh}, \mathrm{Os}, \mathrm{Ir}, \mathrm{Pt}$, and Au. Fields in which AMS has made important contributions include hydrology, geoscience, materials science, biomedicine, sedimentology, dendrochronology, archaeology, environmental sciences, oceanography, paleoclimatology, and several others.

Many review articles have been written on the science of AMS and its applications since its inception in 1977 (see for example Litherland 1980, 1984; Gove 1985; Elmore and Phillips 1987). The historical development of AMS as it currently exists began in 1977. It has been covered in detail in many review articles (see for example Gove 1992, 1999).

\section{International Conferences on Accelerator Mass Spectrometry}

The first international conference on AMS was held at the University of Rochester in 1978. It was titled "Radiocarbon Dating with Accelerators" (Gove 1978) reflecting the above-mentioned impetus for the development of AMS. At that meeting, however, papers on the detection of ${ }^{10} \mathrm{Be}$ and ${ }^{36} \mathrm{Cl}$ were also presented. The title of the meeting was subsequently changed to reflect the wider applications of AMS. In 1981 the Second International Symposium on Accelerator Mass Spectrometry was held at the Argonne National Laboratory (Kutschera 1981). The third meeting took place at Zurich in 1984 (Woelfli et al. 1984), the fourth (which celebrated the Anno Decimo of AMS) was held at Niagara-on-the-Lake, Canada in 1987 (Gove et al. 1987), the fifth in Paris in 1990 (Yiou and Raisbeck 1990), the sixth in Australia in 1993 (Fifield et al. 1994) and the seventh in Tucson, Arizona in 1996 (Jull et al. 1996). The eighth was held in Vienna, Austria in 1999. Except for the first two AMS conferences, the proceedings have been published by North-Holland Publishing Division in Nuclear Instruments and Methods in Physics Research.

The ${ }^{14} \mathrm{C}$ community has held an International Radiocarbon Conference every three years or so, with the 10th held in Bern-Heidelberg in 1979. That was the first of these meetings to include a session on AMS. Papers were presented by the Rochester-Toronto-General Ionex group, the Argonne National Laboratory, Oxford University, the Chalk River Nuclear Laboratories, AERE Harwell, and the University of Washington. The proceedings of these conferences are published in the journal RADIOCARBON, and Renee S Kra, whom this 40th Anniversary Special Issue of RADIOCARBON honors, was its managing editor from 1968 to 1997. It was she, Minze Stuiver, and Austin Long who edited the proceedings of the 10th and many subsequent issues of the proceedings, all of which have contained papers on AMS. The 11th of these conferences was held in Seattle in 1982, the 12th in Trondheim in 1985, the 13th in Dubrovnik in 1988, the 14th in Tucson in 1991, the 15th in Glasgow in 1994, the 16th in Groningen in 1997, and the 17th will be held in Israel in 2000.

Two books have been published on AMS recently. The first is a comprehensive technical account titled Accelerator Mass Spectrometry: Ultrasensitive Analysis for Global Science (Tuniz et al. 1998) and the second is a more popular account From Hiroshima to the Iceman: The Development and Applications of Accelerator Mass Spectrometry (Gove 1999). The first book is divided into three major parts- AMS equipment and techniques, principles of cosmogenic radionuclide production and distribution, and applications of AMS. It addresses in some detail virtually all the technical 
aspects of AMS. The second covers the historical development of AMS and of electrostatic accelerators, the instrumentation for AMS and a number of interesting applications.

\section{Instrumentation for AMS}

Most AMS systems presently employ tandem electrostatic accelerators with cesium negative ion sputter sources. The samples or targets used in these sources are solids, e.g. in the case of ${ }^{14} \mathrm{C}$, a variety of techniques have been devised for converting small organic samples into graphite suitable for use in a sputter source. For radioisotope measurements sample sizes of 1-10 mg are employed, and generally, several samples can be mounted for insertion into the source without disturbing the vacuum system involved. The chemical forms generally used for each of the most common AMS radioisotopes are $\mathrm{BeO}$, carbon (graphite), $\mathrm{Al}_{2} \mathrm{O}_{3}, \mathrm{AgCl}$ and $\mathrm{AgI}$, respectively. The negative ions emerge from the source with energies of $25 \mathrm{keV}$ or so. They are then passed through a magnetic analyzer. The addition of an electrostatic analyzer preceding the magnetic analyzer is used in some installations. The ions are then further pre-accelerated to energies up to a few hundred keV depending on the size of the tandem and injected into the first half of the tandem focused on the stripper canal in the center of the high voltage terminal. The stripper canal is, typically, a differentially pumped tube into which argon gas is fed.

The terminal of the tandem is held at a constant positive voltage ranging from 2 to $10 \mathrm{MV}$. Of the five most commonly measured radioisotopes only ${ }^{36} \mathrm{Cl}$ requires the highest terminal voltage. In the terminal stripper, in the interactions between the energetic negative ions being accelerated and the stripper gas, not only is the extra electron that made the accelerated ions negative removed but additional electrons are stripped off, creating positive ions of charge $3+$ or higher. The multiply charged positive ions then undergo a second acceleration from the terminal to ground.

Positive ion analysis systems vary from one AMS laboratory to another. All of them, however, include both magnetic and electrostatic fields. A variety of detectors are employed following the magnetic and electric deflection analyzers at the high energy end of the AMS systems. The most common for the lightest radioisotopes such as ${ }^{14} \mathrm{C}$ is a $\Delta \mathrm{E}-\mathrm{E}$ Si surface barrier solid state detector. For intermediate mass radioisotopes such as ${ }^{36} \mathrm{Cl}$ a multi-anode gas ionization detector is employed. In such a detector both $\mathrm{E}$ and $\mathrm{dE} / \mathrm{dx}$ are measured and it is possible to discriminate between isobars. In some cases, e.g. for ${ }^{129} \mathrm{I}$, a system for measuring the time of flight of the ions is employed to reduce the interference of tails of ions of nearby mass $\left({ }^{127} \mathrm{I}\right.$ in the case of $\left.{ }^{129} \mathrm{I}\right)$.

AMS measurements consist of establishing the ratio of the counting rate of the radioisotope in question to the current of its stable isotope. Standards of known isotope ratio are run frequently for normalization, and blanks with no detectable radioisotope are employed as a measure of background. Corrections for other effects can be made by comparison with the standards.

Various factors can affect the precision of an AMS measurement, the most important of which is counting statistics. The precision of most AMS measurements lies between $3 \%$ and $10 \% .{ }^{14} \mathrm{C}$ is an exception. Here a well-operated AMS facility can achieve a precision of $1 \%( \pm 83 \mathrm{yr})$ and, if pressed and the sample warrants, $0.5 \%$ or $5 \%$ ( $\pm 41 \mathrm{yr})$ or even better.

There were 39 full-time or part-time AMS laboratories throughout the world in 1999. All but two employ tandem electrostatic accelerators. Of these 37, sixteen have terminal voltages between 2.5 and $3 \mathrm{MV}$, ten between 5 and $6 \mathrm{MV}$, five between 8 and $9.5 \mathrm{MV}$, and six between 12 and $20 \mathrm{MV}$. Except for AMS measurements of ${ }^{36} \mathrm{Cl}$, which require tandems with terminal voltages of $8 \mathrm{MV}$ or higher (to resolve the stable isobar ${ }^{36} \mathrm{~S}$ ) all other light and heavy radioisotopes and stable isotopes 
can be readily measured with tandems having terminal voltages as low as $2.5 \mathrm{MV}$. Some of the interesting measurements made recently by AMS follow.

\section{The Atomic Bombing of Hiroshima}

The bomb that leveled Hiroshima was dropped on August 6, 1945. By the end of the year, 140,000 people in that city were dead. It was one of a kind and so had never been tested. It employed a gun barrel in which a "bullet" of the rare isotope of uranium, ${ }^{235} \mathrm{U}$, was fired against a ${ }^{235} \mathrm{U}$ target. By the mid 1980s there were approximately 60,000 Japanese citizens who had been exposed to and survived the radiation from the Hiroshima bomb. These survivors as well as the ones from the bombing of Nagasaki are the best studied human beings in history in terms of the short- and long-term effects of nuclear radiation. For such studies to be meaningful, however, one must have a good estimate of the nature and degree of the nuclear radiation they received. In the case of the Hiroshima bomb no one knew with any accuracy at all what its neutron and gamma-ray yield might have been.

Computer modeling was carried out in 1986 to predict these yields. The gamma-ray intensity emitted in the explosion could be measured as a function of distance from the explosion by a technique called thermoluminescence dosimetry. These measurements were made in roof tiles some omniscient Japanese scientists had collected and stored, carefully cataloging them according to their distance from the bomb's hypocenter and the extent to which they were shielded from the bomb by nearby buildings. The computer calculations were in general agreement with the measured gammaray intensities. These calculations, however, showed that neutrons played virtually no role in the radiation damage to humans.

It was realized in the late 1980s by scientists at the Lawrence Livermore National Laboratory (LLNL) in California and at the Technical University in Munich, Germany that ${ }^{36} \mathrm{Cl}$ produced by neutron capture in ${ }^{35} \mathrm{Cl}$ was ideal for measuring the bomb neutrons. Chlorine is reasonably ubiquitous and can be found, at low concentrations, in building materials in Hiroshima that survived the nuclear holocaust. Because ${ }^{36} \mathrm{Cl}$ has such a long half life $\left(3 \times 10^{5} \mathrm{yr}\right)$ whatever amount of it was produced in 1945 is still there to this day.

A collaboration between scientists at Hiroshima University and the Technical University of Munich, using the Munich AMS facility, resulted in the measurement of the ${ }^{36} \mathrm{Cl}$ to chlorine ratio (and thus the slow neutron fluence) in a granite gravestone $107 \mathrm{~m}$ from the hypocenter (slant range of $590 \mathrm{~m}$ ) of the Hiroshima explosion (Kato et al. 1988). Although the measurement is interesting it gives no clues about the effect of such neutron doses on humans since everyone at that distance from the explosion died instantly from blast and heat.

At the suggestion of a scientist at LLNL, five samples of building material collected from Hiroshima at slant ranges varying from 650 to $1700 \mathrm{~m}$ were measured at Rochester. When the results were translated into thermal neutron flux densities they showed that a person at the $650 \mathrm{~m}$ distance would have received a blast of neutrons in the split second of the explosion equal to the thermal neutron dose permitted for human beings to receive in a period of over $500 \mathrm{yr}$. Even at the largest distance of almost $2 \mathrm{~km}$ the neutron flux density was equivalent to a permitted thermal dose of $2 \mathrm{yr}$. The latter was almost a factor of 100 greater than the computer calculations had indicated. It was neutrons that had made the major contribution to the radiation damage suffered by the Hiroshima survivors, after all, and not gamma rays. This data was of the greatest significance and was published in the journal Health Physics (Straume et al. 1992). 
More recently, additional measurements of the ${ }^{36} \mathrm{Cl}$ to stable chlorine ratio have been made at the Livermore AMS laboratory on Hiroshima samples (Straume 1993). The results agree with the original Rochester data and now present a reasonably complete picture of the slow neutron fluence emitted by the Hiroshima atom bomb over distances at which there were substantial numbers of survivors.

What remains to be done is to evaluate the new information on the radiation these Hiroshima survivors actually received and to compare the doses received with the biological damage that resulted. It seems remarkable that it took almost 50 years for this to happen —and it would not have happened yet but for the development of AMS in 1977.

\section{The Initial Peopling of the Americas}

One of the great contributions that carbon dating in general, and AMS carbon dating in particular, has made is establishing the dates of early human habitations. Such sites contain flint artifacts used for weapons and tools, animal and human bones in which, occasionally, are found imbedded flint weapon points, and camp fire sites containing samples of carbon from wood that was contemporary with the time the fires were used. Many times the samples of both bone and carbon are so small that only AMS can provide a date.

Many such human habitation sites have been found in North and South America. In North America the oldest sites dating back almost 13,000 years are found in Alaska. Other sites are found in Montana, Wyoming, South Dakota, Colorado, Oklahoma, New Mexico and Arizona and they have later dates of around 12,000 yr. This strongly suggests that early humans crossed from Siberia to Alaska via the Bering Strait, which at the time may have had a land bridge, and moved south via a corridor that existed between the Laurentide and Cordilleran ice sheets well before the last ice age ended some 7000 years ago.

Two fairly recent discoveries in this connection are particularly noteworthy. The first is the discovery of a site of human habitation in Monte Verde, Chile. Monte Verde is some 575 miles south of Santiago, Chile and, as the crow flies, some 20,000 miles from the Siberian-Alaskan land bridge. The site has been carbon dated to be some 13,500 years old or perhaps even older (Dillehay 1989, 1997). It is at the southern limit of continental Chile approximately 30 miles east of the shores of the Pacific Ocean. Further south complex waterway channels and islands stretch some 600 miles to Tierra del Fuego. It seems a most unlikely site for the oldest habitations of people in the Americas, raising as it does the question of how its inhabitants could possible have gotten there.

The second discovery, in the summer of 1996 on the banks of the Columbia River near Kennewick, Washington some 230 miles from the river's mouth on the Pacific Ocean, was what eventually became a 90-95\% complete skeleton of a man (Gibbons 1996). The land on which the skeleton was discovered is owned by the Army Corps of Engineers. The skeleton had two fascinating aspects: a projectile point was imbedded in his pelvis and, morphologically, his skull did not look Native American-his features were caucasoid. Collagen, extracted from a sliver of bone was measured in the AMS laboratory at LLNL (R E Taylor, personal communication 1997). It was some 9000 years old. It is believed that the bone sliver is so well preserved that it may be possible to extract and analyze DNA. Such a test could answer the question of to what group of people Kennewick belonged. Was he Caucasian or an Asian ancestor of American Indians? The Confederated Tribes of the Umatilla Indian Reservation, the local group of Native Americans, made the astonishing claim that he was an ancestor and should undergo ceremonial internment. All further tests are suspended pending a decision by the appropriate court. 


\section{The Neolithic Iceman}

In September 1991, two German hikers discovered a frozen corpse in the Similaun glacier of the Alps on the border between Austria and Italy 10,500 feet above sea level. Dubbed the Iceman, the corpse resembled the emaciated and shrunken bodies found in concentration camps at the end of World War II. When it was finally freed from its icy tomb the body, still frozen solid, and a number of artifacts found with it were transported to the Research Institute for Alpine Studies in Innsbruck (Spindler 1993). The artifacts included a 10-cm copper ax head with its handle and bindings intact, a 1.82-m-long incomplete wooden bow made of yew but broken during the body's recovery, eleven $85 \mathrm{~cm}$-long arrows - two of them tipped with double-faced flint points, the world's oldest quiver made from deer skin, an ash-handled flint dagger with its grass sheaf, a bone needle, and a $25-\mathrm{cm}$ stick tipped with an antler.

This remarkable find constituted one of the major anthropological discoveries of the century. As such it was of paramount importance to establish its age. Carbon dating was clearly the way to do so. However, before the development of AMS, an unacceptably large sample of his flesh and bones would have been required for radioactive decay counting by the Libby method exclusively employed up to 1977. However, AMS was by then and had been for many years a mature science and could be safely employed to date the Iceman with minimal destruction of precious material.

A number of European carbon dating laboratories were involved, including Gif-sur-Yvette in France, Oxford in England, Uppsala in Sweden, and Zurich in Switzerland. Excellent agreement was obtained by the four laboratories. Because of wiggles in the ${ }^{14} \mathrm{C}$ dendrochronology calibration curve, the age of the Iceman could not be pinned down with the accuracy inherent in AMS. The best that can be said is that he died between 3110 and $3370 \mathrm{BC}$, or some 5240 years ago. The botanical material was also carbon dated and the results have been published (Prinoth-Fornwagner and Niklaus 1994).

\section{Other Recent AMS Results}

The above are but three of many areas of recent research that have benefited from the power of AMS. Others include the measurement of the leakage of nuclear waste from US Department of Energy nuclear fuel reprocessing plants at the Savannah River Site in South Carolina, the Hanford Reservation in Washington, the Idaho National Engineering Laboratory in Idaho, and West Valley in New York (see references in Gove 1999, chapter 9). Measurements of ${ }^{36} \mathrm{Cl}$ and ${ }^{129} \mathrm{I}$ by AMS in the soil and water in the vicinity of these plants shows that the some 11 million cubic feet of high-level nuclear waste distributed between them is leaking into the environment.

Other measurements by AMS include the age of the Turin Shroud-the reputed burial cloth of Christ (640 years old) (Gove 1996), the Dead Sea scrolls (some 2000 years old), the Elephant Bird egg found in Australia in 1993 (1970 years old), and many other ${ }^{14} \mathrm{C}$ dating results.

Another important application of AMS lies in the field of biomedicine. This application was first suggested by two scientists at the University of Rochester's Medical School in 1978 (Keilson and Waterhouse 1978). However, it took some 10 years before actual biomedical research employing AMS began. The pioneering work in this field was carried out at the Center for AMS at LLNL in California and the results of this and other AMS groups have been presented at AMS conferences beginning with the fifth in Paris in 1990 as well as in many other medical related journals. 


\section{Thoughts on Future Developments in AMS}

Two possible new developments will be described. The first involves ${ }^{14} \mathrm{C}$ background measurements of interest in connection with the very large volume scintillation detectors planned, being built or in operation as neutrino detectors. The second involves the use of neutral ion injection for AMS (NI AMS).

It was mentioned above that one of the reasons for developing AMS for the detection of ${ }^{14} \mathrm{C}$ was the hope that it could date organic samples that "died" much longer ago than the 60,000-year or so age limit of the Libby decay counting method. Since the latter limit is probably due to cosmic ray background in the counters used to detect the $\beta$-decay of ${ }^{14} \mathrm{C}$ and $\mathrm{AMS}$ equipment is not sensitive to such a background, AMS measurements should date back much further in time, perhaps to as far back as 100,000 years. Carbon of contemporary organic origin has a ${ }^{14} \mathrm{C} / \mathrm{C}$ ratio of $1.2 \times 10^{-12}$. The ratio for 60,000 -yr-old carbon is $8.5 \times 10^{-16}$. That for 100,000 -yr-old carbon is $6.7 \times 10^{-18}$. An analysis of the background for ${ }^{14} \mathrm{C}$ AMS has been made at the University of Toronto's AMS laboratory (Beukens 1992). The ${ }^{14} \mathrm{C} / \mathrm{C}$ ratio in a blank aluminum sample was $2.5 \times 10^{-17}$. The ratio in several samples, one from $\mathrm{CO}_{2}$ from natural gas, one from marble supplied by the IAEA, and one from anthracite, were statistically similar and yielded a value of about $10^{-15}$. Some decay counting laboratories achieve values this low or lower. These ratios, however, are considerably higher than one would expect in the samples tested.

Some ${ }^{14} \mathrm{C}$ must be present in natural gas and petroleum due to the very low levels of muons and natural radioactivity in many locations deep in the earth. Estimates of the ratio ${ }^{14} \mathrm{C} / \mathrm{C}$ are near $10^{-20}$ from such sources and will vary greatly due to the presence or absence of nearby uranium or thorium deposits. The lowest ratio measured by AMS was $10^{-18}$ in 1991 at the University of Toronto's IsoTrace Laboratory (R P Beukens and R S Raghavan, personal communication 1991). The sample was carbon monoxide obtained from natural gas enriched in ${ }^{14} \mathrm{C}$ by a factor of $10^{4}$. The material was supplied to IsoTrace for analysis in connection with the Borexino project at the Gran Sasso underground laboratory. Later, reported in 1998, the $4 \mathrm{Mg}$ test liquid scintillator there recorded a level of $2.0 \times 10^{-18}$ for ${ }^{14} \mathrm{C} / \mathrm{C}$ by decay counting (Alimonti et al. 1998). This is the lowest ${ }^{14} \mathrm{C}$ abundance ever measured in a non enriched sample. It is believed that the above AMS ratio of $10^{-18}$ in the enriched $\mathrm{CO}_{2}$ sample can be reduced to $10^{-20}$ or better. This is highly desirable for three interconnected reasons: 1) The choice of carbon for liquid scintillators, for neutrino measurements, will be facilitated, 2) the ${ }^{14} \mathrm{C}$ background and contamination in AMS dating work will be better understood, and 3 ) the variability of the deep underground production of ${ }^{14} \mathrm{C}$ can be studied.

The second possible future development involves neutral injection for AMS (NI AMS). This possibility has been suggested previously (Litherland and Kilius 1997; Litherland et al. 1999).

When the electron affinity of a nuclide is low or negative, or when the wanted nuclide is imbedded in an insulator, the initial production of singly charged positive ions directly in an ion source or by bombardment by negative ions is highly advantageous. Neutral injection involves converting efficiently these positive ions to neutrals by resonant electron transfer. The cross sections for the formation of neutral atoms from singly charged ions are very large when the projectile ions collide with stable atoms of the same species or when the binding energies of the electrons of the projectile ion are close to those of the ground or an excited state of the bombarded stable ions of a different species. The resulting neutral ions are then injected into a tandem electrostatic accelerator. Singly charged positive ions are readily produced for most atoms and molecules unlike the situation for negative ions. 
Neutral injection of atoms and molecules of the same mass to the terminal of a tandem followed by a charge change to $1+$ in the terminal and then followed by a charge change to $3+$ at ground (needed for molecular breakup of the molecular isobar(s) has an additional advantage over standard AMS (negative ions injected into the tandem followed by charge change to $3+$ in the terminal). It affords a better mass energy product separation between the wanted atom and the molecular fragments from the molecular isobar.

When the wanted atoms are imbedded in an insulator, for example metals in a silicate rock matrix, the use of singly charged positive Cs ions to bombard the insulator to produce the wanted singly charged negative ions produces a buildup of charge. This causes voltage instabilities that invalidate the measurements. When negative ions are employed to bombard the insulator to produce the wanted singly charged positive ions there is little or no buildup of charge. This is probably due to the mobility of the electrons created by the negative ion bombardment and their being driven off by the electric field of the negative ions.

The vast majority of elements in the periodic table have either low or negative electron affinities (the binding energy for attaching an electron to a neutral atom). Most of these can readily be produced as singly charged positive ions. They include the lanthanides $(Z=57-71)$, the transition elements $(Z=21-30, Z=39-48$, and $Z=72-80)$, the noble gases $(Z=10,18,36,54$ and 86$)$ and the actinides ( $Z$ greater than or equal to 89 ). There are other special cases such as cesium isotopes that are more easily formed as singly charged positive ions than singly charged negative ions and many of the platinum group elements (PGE) - a sub set of the transition elements - whose detection at very low levels in situ in insulating rock matrices is of importance.

NI AMS, if implemented, might well constitute a new revolution in accelerator mass spectrometry.

\section{ACKNOWLEDGMENTS}

I would like to acknowledge invaluable discussions with A E Litherland, R P Beukens and other colleagues at the University of Toronto's IsoTrace Laboratory, and K H Purser of Southern Cross Corporation. I would also like to pay tribute to Renee Kra for her sterling editorial contributions to the field of radioisotope measurements, particularly radiocarbon, and to her charm and her indomitable spirit.

\section{REFERENCES}

Alimonti $\mathrm{G}$ et al. 1998. Measurement of the ${ }^{14} \mathrm{C}$ abundance in a low-background liquid scintillator. Physics Letters B422:349-58.

Beukens RP. 1992. Radiocarbon accelerator mass spectrometry: background, precision and accuracy. In: Taylor RE, Long A, Kra RS, editors. Radiocarbon after four decades: an interdisciplinary perspective. New York: Springer-Verlag. p 23-239.

Dillehay, TD, editor. 1989. Monte Verde, a late pleistocene settlement in Chile. Vol I. The archaeological context. Washington DC: Smithsonian Institution Press.

Dillehay TD, editor. 1997. Monte Verde, a late pleistocene settlement in Chile. Vol II. Paleoenvironmental and site context. Washington DC: Smithsonian Institution Press.

Elmore D, Phillips FM. 1987. Accelerator mass spec- trometry for measurements of long-lived radioisotopes. Science 236:543-50.

Fifield LK, Fink D, Sie SH, Tuniz C, editors. 1993. Proceedings of the 6th International Conference on Accelerator Mass Spectrometry. Nuclear Instruments and Methods in Physics Research B92:1-524.

Gibbons A. 1996. The peopling of the Americas. Science 274:31-3.

Gove HE, editor. 1978. Proceedings of the first conference on radiocarbon dating with accelerators. Rochester, NY: University of Rochester.

Gove HE. 1985. Accelerator-based ultrasensitive massspectrometry. In: Bromley DA, editor. Treatise on heavy ion science. Volume 7. New York: Plenum Press. p 431-563.

Gove HE. 1992. The history of AMS, its advantages over decay counting: applications and prospects. In: Taylor 
RE, Long A, Kra RS, editors. Radiocarbon after four decades: an interdisciplinary perspective. New York: Springer-Verlag. p 214-29.

Gove HE. 1996. Relic, icon or hoax? carbon dating the Turin Shroud. Bristol and Philadelphia: Institute of Physics Publishing. 336 p.

Gove HE. 1999. From Hiroshima to the Iceman: the development and applications of accelerator mass spectrometry. Bristol and Philadelphia: Institute of Physics Publishing. $226 \mathrm{p}$.

Gove HE, Litherland AE, Elmore D, editors. 1987. Proceeding of the 4th International Symposium on Accelerator Mass Spectrometry. Nuclear Instruments and Methods in Physics Research B29:1-455.

Jull AJT, Beck JW, Burr GS, editors. 1996. Proceedings of the 7th International Conference on Accelerator Mass Spectrometry. Nuclear Instruments and Methods in Physics Research B123:1-612.

Kato K, Habara M, Aoyama T, Yoshizawa Y, Biebel U, Haberstock G, Heinzl J, Korschinek G, Morinaga H, Nolte E. 1988. Measurement of the neutron fluence from the Hiroshima atomic bomb. Journal of Radiation Research 29:261-6.

Keilson J, Waterhouse C. 1978. Possible impact of the new spectrometric techniques on ${ }^{14} \mathrm{C}$ tracer kinetic studies in medicine. In: Gove HE, editor. Proceedings of the 1st Conference on Radiocarbon Dating with Accelerators. University of Rochester. p 314-9.

Kutschera W, editor. 1981. Proceedings of the Symposium on Accelerator Mass Spectrometry. ANL/PHY 81-1. Springfield: National Technical Information Service, US Department of Commerce.

Litherland AE. 1980. Ultrasensitive mass spectrometry with accelerators. Annual Reviews of Nuclear and Particle Science 30:437-73.

Litherland AE. 1984. Accelerator mass spectrometry. Nuclear Instruments and Methods in Physics Research B5:100-8.

Litherland AE, Kilius LR. 1997. Neutral injection for AMS. Nuclear Instruments and Methods in Physics
Research B123:18-21.

Litherland AE, Purser KH, Gove HE. 1999. Neutral injection for radioactive beams and accelerator mass spectrometry. In: Shepart KW, editor. CP473, Heavy Ion Accelerator Technology: 8th International Conference. The American Institute of Physics.

Prinoth-Fornwagner R, Niklaus Th R. 1993. The man in the ice: results from radiocarbon dating. Nuclear Instruments and Methods in Physics Research B92:282_ 90.

Purser KH, Liebert RB, Litherland AE, Beukens RP, Gove HE, Bennett CL, Clover MR, Sondheim WE. 1977. An attempt to detect stable $\mathrm{N}^{-}$ions from a sputter ion source and some implications of the results for the design of tandems for ultra-sensitive carbon analysis. Revue de Physique Appliquee 12:1487-92.

Spindler K. 1993. The Iceman's last weeks. Nuclear Instruments and Methods in Physics Research B92:27481.

Straume T. 1993. Neutron discrepancies in the DS86 dosimetry system have implications for risk estimates. RERF Update 4:3-4 (Hiroshima: Radiation Effects Research Foundation).

Straume T, Egbert SD, Woolston WA, Finkel RC, Kubik PW, Gove HE, Sharma P, Hoshi, M. 1992. Neutron discrepancies in the DS86 Hiroshima dosimetry system. Health Physics 63:421-6.

Thompson JJ. 1912. XIX Further experiments on positive rays. Philosophical Magazine 24:209-53.

Tuniz C, Bird JR, Fink D, Herzog GF. 1998. Accelerator mass spectrometry: ultrasensitive analysis for global science. Boca Raton, Florida: CRC Press. 371 p.

Woelfli W, Polach HA, Anderson HH, editors. 1984. Proceedings of the 3rd International Symposium on Accelerator Mass Spectrometry. Nuclear Instruments and Methods in Physics Research B52:91-448.

Yiou F, Raisbeck GM, editors. 1990. Proceedings of the 5th International Conference on Accelerator Mass Spectrometry. Nuclear Instruments and Methods in Physics Research B52:211-630. 